Worcestershire seem to be compounded of Welsh and Eastern elements.

Over much of that part of the WarwickshireStaffordshire Plateau which is drained by the upper waters of the Tame, Cole and Blythe, the mantle of drift is comparatively intact, and frequently forms the valley floors; but on the Severn-Avon side of the watershed of England it becomes very ragged, projecting outwards as promontories or forming outliers on the highest hills. This is so far a rule that one is forced to view the capping as remnants of a more or less continuous sheet which once stretched far into the vales of Severn and Avon. Here it has in most places been completely destroyed. Evidence of its presence must be sought for on the hill-tops and not in the valleys, all of which in their present state are younger than the glaciation.

It is, I think, fair to conclude that the ice sheets at their maxima occupied the vales, and that these were far shallower then than now. This hypothesis sounds very speculative, but there are some remarkable pieces of evidence in its favour*.

\section{The River Terraces as Evidence OF THE STAGES IN THE EROSION}

If we are right in claiming a former far wider distribution of the drifts than the areas where they now occur in force, the river valleys should provide a great deal of evidence concerning the way in which their destruction has been brought about. In the present case this is certainly so ; for we have in the Severn and its tributaries a wonderfully developed system of river terraces and of deposits that originated under the rigorous conditions of glacial climates, the so-called taele gravels and melt-water flood gravels.

The farther we go from the plateau and from the drift-covered ground on its north-west and eastern sides the greater the number of high-level terraces. In some cases the geographical distribution and the lithological composition enable us to relate a terrace to a particular set of glacial

* The evidence is discussed in the printed address. deposits. These points are brought out by the accompanying table.

\begin{tabular}{|c|c|c|c|c|c|}
\hline \multirow{2}{*}{ Severn } & \multirow{2}{*}{ Avon* } & \multirow{2}{*}{$\begin{array}{l}\text { Height at } \\
\text { Mouth of } \\
\text { Severn } \dagger\end{array}$} & \multicolumn{2}{|c|}{ Upstream Limit } & \multirow{2}{*}{$\begin{array}{l}\text { Compo- } \\
\text { sition }\end{array}$} \\
\hline & & & Severn & Avon & \\
\hline Woolridge & - & ? about 200 & Tewkesbury & - & $B, ? W, M^{* *}$ \\
\hline $\begin{array}{c}\text { Bushley } \\
\text { Green }\end{array}$ & No. 5 & 110/75 0.D. & Tewkesbury & Stratford & $\begin{array}{c}\text { a few } b^{\prime} \\
\text { do. }\end{array}$ \\
\hline $\begin{array}{l}\text { Green } \\
\text { Kidder- } \\
\text { minster }\end{array}$ & No. 4 & 65/35 O.D. & $\begin{array}{l}\text { Bewdley } \\
\text { (goes up } \\
\text { Stour) }\end{array}$ & $\begin{array}{c}\text { Stone- } \\
\text { leigh near } \\
\text { Kenil- } \\
\text { worth }\end{array}$ & do. \\
\hline Main & $\begin{array}{l}\text { Nos. } 2 \\
\& ? 3\end{array}$ & $35 ? / 15 ?$ O.D. & $\begin{array}{l}\text { Coalport } \\
\text { (goes up } \\
\text { Worfe) }\end{array}$ & $\begin{array}{l}\text { Church } \\
\text { Lawford } \\
\text { near } \\
\text { Rugby }\end{array}$ & do. and $S$ \\
\hline Worcester & ? No. 1 & $?-25$ O.D. & Shrewsbury & $?$ & do., do. \\
\hline
\end{tabular}

* Miss Tomlinson's nomenclature. † Height of top/height of base. ${ }^{* *} B$, Bunter Pebbles; $W$, Welsh; $F$, Flints; $M$, Malvernian ; $S$, Scottish and Lake District.

I have elsewhere discussed the extremely ambiguous evidence bearing on the question whether there was an interglacial episode between the time of the Main and Worcester Terraces, without being able to obtain an assured answer. On the other hand, the fauna of Avon No. 4 is a warm climate one, which makes it probable that both it and its correlative, the Kidderminster Terrace, are interglacial. The position of Avon No. 4 Terrace below Avon No. 5 which connects with the Great Eastern glaciation, and above the terraces, Avon No. 2 and ? No. 3, which correlate with the Main Terrace of the Severn and so with the Irish Sea glaciation, forces us to conclude that these two glaciations were not contemporaneous.

Various lines of evidence converge, therefore, towards the following conclusion: that the Bushley Green-Avon No. 5 Terrace and the still higher Woolridge Terrace are to be correlated with the 'Older Drifts'; that the Main, the Worcester, and Avon No. 2, and possibly Avon No. 3, Terraces, belong to the 'Newer Drifts' ; and that the Kidderminster-Avon No. 4 Terrace records the intervening 'Great Interglacial.' The question whether the older drifts of the Midlands bridge more than one glacial epoch is dealt with in the sequel.

[To be continued.]

\title{
Mechanism of the Photographic Process
}

A GENERAL discussion on "The Mode of
Section A of the British Association meeting
at Nottingham, was opened by three speakers,
who treated the problem of photography from
three different points of view. Mr. E. R. Davies
drew a picture of the action of light on photo-
graphic materials mainly from physical evidence.
Dr. S. O. Rawling gave an account of the action and theory of development. Prof. N. F. Mott described a theory of light action and latent image formation which was developed on a wavemechanical basis and which provides an explanation for many hitherto puzzling facts and a useful working hypothesis.

The sensitive layer of any piece of photographic material consists of a thin film of gelatin in which is embedded an enormous number of minute 
crystals of a silver halide. Silver bromide is most commonly used and is precipitated in the course of manufacture in a gelatin sol. After various operations which greatly affect the sensitivity to light, the so-called emulsion is spread out on a support and dried down to form a layer about 1/1000 in. in thickness.

The light-sensitive unit in the photographic layer is the individual silver halide crystal. Its sensitivity manifests itself in two ways. Sufficient exposure to light causes the crystal to darken visibly-print-out effect. Exposures smaller by a factor of $1 / 10^{8}$ produce the 'latent image', which makes the crystals developable.

The print-out effect consists of the direct production of silver by the action of light, with liberation of the halogen. If this can be taken up by the surrounding medium the process will proceed to completion. Two points were emphasized. The quantum efficiency is of the order of one silver atom formed per absorbed quantum of light. Light is absorbed all over the crystal, but the silver coagulates and forms specks.

The latent image provides the ever-new problem in photography which cannot yet be regarded as solved. No satisfactory proof of its nature has so far been offered, although the print-out effect strongly suggests that it consists of specks of metallic silver. A few to a few hundred light quanta must be absorbed to make a grain developable. It is difficult to say what effect so few silver atoms could have unless they coagulate to form a speck. Since there is so far no sufficiently sensitive physical method by which the latent image can be detected, we have to use the results of development for its interpretation. A thorough under. standing of the process of development is therefore essential.

The latent image acts as a trigger or a catalyst, which enables the developer to reduce the silver halide crystal. Practically all the energy required is supplied chemically, and the latent image itself is lost in the process of development. Developers are often regarded as solutions possessing certain redox potentials. (In the physicist's language, the term redox potential may be explained by saying that the potential measures the ease with which electrons are given off by the solution, a low potential meaning a stronger reducer, giving off electrons more easily.) If the potential is too low, silver halide crystals will be reduced indiscriminately, whether they carry a latent image or not: if the potential is too high, they will not be developed at all. By preparing a series of solutions of decreasing potential it can be shown that at a certain critical potential no development takes place; below that a solution will act as a developer; above it as an oxidizer, destroying the latent image. Similar results are obtained on a partly developed piece of photographic material, which, of course, contains bigger particles of silver. At another critical potential no change occurs ; above it the density is diminished, below it further development occurs. This critical potential is higher than that of the latent image. The conclusion from these experiments is that the latent image silver speck must be above a certain critical size-which cannot, however, be worked out from these data-but below the size at which it would act as solid silver.

These thermodynamical considerations do not tell us anything about the actual mechanism of development. Two essentially different processes have been suggested. One is that the silver halide is dissolved, is reduced to silver in the solution, which soon becomes supersaturated with reduced silver, and the supersaturation is relieved by deposition of silver upon the latent image. From the behaviour of artificially produced silver particles it has been estimated that an aggregate of four or five atoms of silver may be necessary for this action to occur. The other suggestion is that the developer, while not being adsorbed by the surface of silver bromide, which is negatively charged, is strongly adsorbed by a speck of latent image, and from this foothold is able to reduce the rest of the crystal, either through the body or at the interface between crystal and developer. Experiments have shown that some of the commonly used developing agents, which yield negatively charged reducing ions, are indeed only feebly adsorbed to negatively charged silver bromide but are strongly adsorbed to colloidal silver, and that by this very adsorption their reducing activity is enhanced. These facts lend strong support to the second hypothesis.

It is, however, probable that both mechanisms can operate, sometimes together. With some developers, yielding positively charged ions, the deposition mechanism probably operates almost exclusively, and we then have the slow, so-called physical development. With other developing solutions the adsorption mechanism, with direct reduction at the interface between silver and silver bromide, may predominate. This seems to be the more likely action with ordinary com. mercial development.

Another mechanism is based on the fact that the negative charge on colloidal silver particles is discharged by light, when the particles become developable. A similar process may occur in the bigger silver halide crystals.

Development always takes place in two seemingly definite steps : an induction period, in which no visible changes occur, and the development 
proper, which proceeds very rapidly. Unless special precautions are taken, a crystal is either found to be completely developed or not at all. The process of development seems to be an autocatalytic reaction, but the significance of this for the mechanism of development is not clear.

We are thus led to the assumption that the latent image consists of a silver speck of critical size.

The formation of this silver speck was then considered. Light is absorbed all over the crystal and forms isolated silver atoms, which then coagulate into a speck. The distinction was drawn between a primary process, the formation of silver atoms, and a secondary process, the coagulation.

The primary process in latent image formation is strongly influenced by changing the absorption of the individual silver halide crystal. This can be done by dyeing the emulsion with 'sensitizing dyes'. The natural absorption of silver bromide in the ultra-violet and the blue, and with it its spectral sensitivity, can be extended right into the red and infra-red. Silver bromide containing a few per cent of silver iodide is much more sensitive than pure silver bromide; this probably also influences the primary process. The absorption spectrum has mostly been found to coincide with the spectral sensitivity of an emulsion. Sensitizing dyes are always strongly adsorbed to silver halide : an intimate contact between dye and crystal seems essential.

The secondary processes strongly influence the sensitivity, that is, the number of quanta required to be absorbed to make the crystal developable. The sensitivity of crystals increases with their size: coarse grain materials are more sensitive. The explanation is not solely that a bigger crystal will absorb more light and thus form a bigger speck more easily, because it has been found that crystals of the same size differ widely in their sensitivity, which is also influenced by the gelatin and foreign substances generally. The active medium is found to be mainly silver sulphide. There has been much speculation as to the way it acts. Silver sulphide probably forms specks on the surface of the silver halide crystals and acts as a condensation nucleus. Much evidence, mainly of chemical nature, confirms this hypothesis.

Here the present writer would point out that, while the latent image in photographic materials cannot be detected by physical methods, there exists a seemingly strict analogy in big single crystals of silver halide. On illumination with blue light they become coloured and develop an absorption band in the red. On illumination with red light this absorption band is bleached out. This corresponds to the Herschel effect on photographic materials, where the latent image is bleached out by consequent exposure to red light. Furthermore, the spectral sensitivity of the Herschel effect coincides well with the absorption band observed in single crystals, suggesting strongly that the particles responsible in both cases must be the same. The particles in single crystals are usually regarded as colloidal silver particles, the absorption band being due to colloidal scattering. This, however, leads to impossible dimensions for the silver particles, which cannot, from photographic evidence, be bigger than a few hundred silver atoms. The absorption band observed in single crystals cannot, therefore, be due to colloidal scattering, but must be caused by a more specific absorption process arising from the intimate contact between the silver speck and the silver halide crystal.

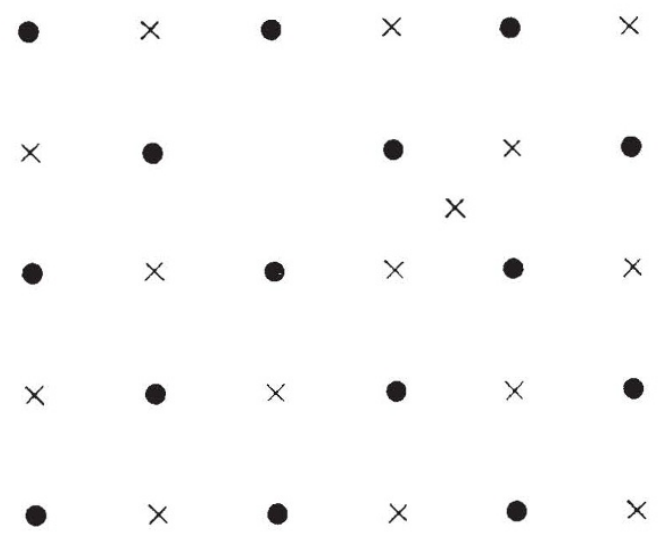

Fig. 1 .

Ionic Condectivity in the Silver Halide rattice.

The mechanism of latent image formation was then considered. The crystals are made up from silver and halide ions. In order to produce a silver atom we have to remove an electron from a bromine to a positively charged silver ion. This act is thought to constitute the primary process in photography. In dye sensitization the electron may come from the dye molecule instead. The fact that silver halides are photo-conductors shows that the electron is not very strongly attached to the silver ion, and may move about in the lattice. Calculations show that the mobility of such an electron is almost as high as in a metal.

A speck of silver in contact with a silver halide crystal was considered. There is a certain probability for some electrons to escape from the silver into the crystal, and an electron vapour pressure is set up which depends on the temperature. The speck thus becomes positively charged. The sensitivity specks of silver sulphide may behave in a similar way. Illumination with light increases 
the electron concentration in the crystal. If this concentration is higher than the equilibrium concentration of the speck, electrons condense on it. The speck becomes negatively charged and tends to attract the positive silver ions. Silver halides are also ionic conductors; the conductivity is entirely due to the silver ions. A mechanism has been suggested for this ionic conductivity which is illustrated by Fig. 1. At any temperature there are some silver ions in the wrong position in the centre of the cube of four others, leaving an empty space in the lattice behind them. These silver ions have a certain mobility, and so have the holes whence they came. The ions will be attracted by the charged silver or silver sulphide speck and will increase its size, pushing it out of the grain. We

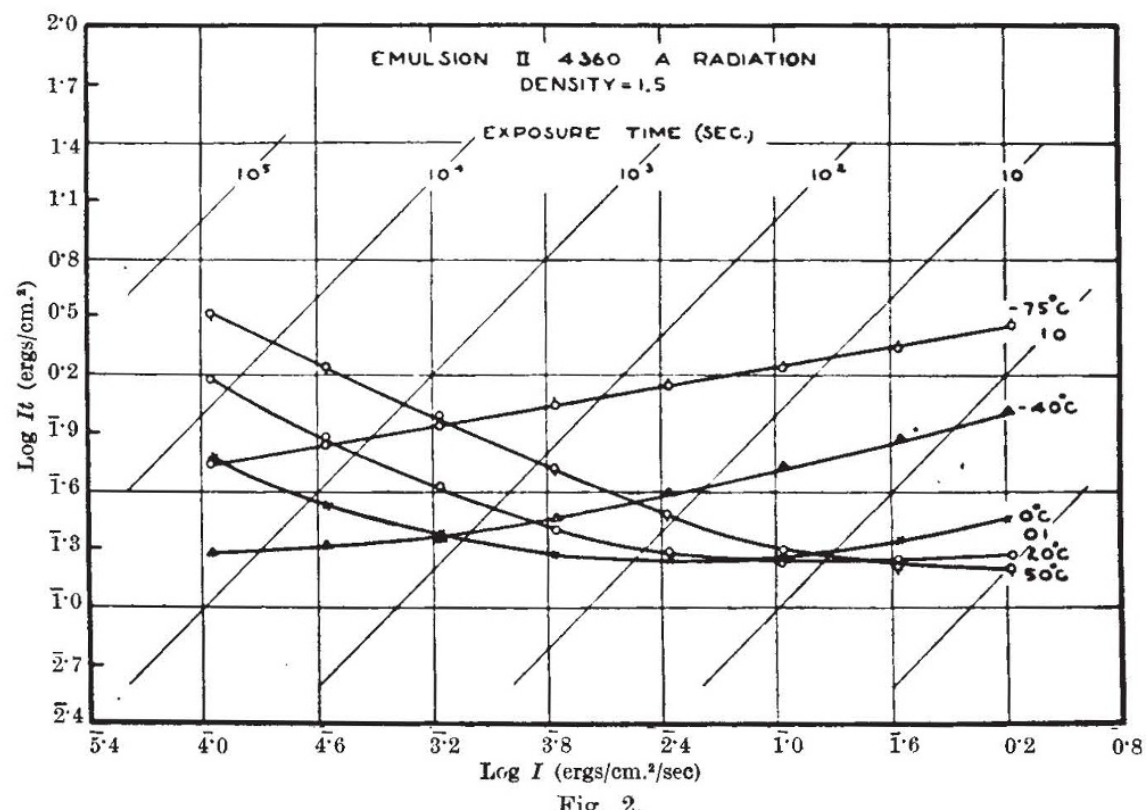

VARIATION OF THE RECIPROCITY CHARACTERISTIC WITH TEMPERATURE.

certain density after development, against the intensity, that is, the rate at which the quanta are received. Two facts are most striking; that there is an optimum intensity where a minimum of exposure is necessary, and that with lowering of the temperature the material becomes more sensitive at low intensities-a fact which should be most valuable for spectrography. Since a critical electron vapour pressure has to be reached before the latent image can be formed, at sufficiently low intensities no latent image may be formed at all ; since there is a certain chance for recombination of the electrons with the bromine atoms the critical vapour pressure may never be reached. On raising the intensity the critical pressure will be reached for the more sensitive grains in the material, but not for others; on raising it still further the optimum will be reached. At high intensities there is no difficulty in reaching a sufficiently high vapour pressure, but since the ionic processes take time, it is not unreasonable to assume that the vapour pressure has to be kept up as long as possible for the optimum effect. For too short exposures the ions have no time to move up to the speck, and recom. bination will take place more readily. At low tem. peratures the critical vapour pressure is more easily reached, and the biggest effect is obtained at low in. tensity when the pressure is kept up for a long time.

are now left with a neutral bromine atom and a spare hole whence the silver ion came. There is reason to assume that the primary process mostly takes place on the surface of the crystal, so that the bromine atom escapes into the gelatin. Only a slight reshuffle of the lattice is necessary to get rid of the hole, when the crystal will be smaller by one ion pair.

The ionic movements take some time and are dependent on temperature, and it is therefore not surprising to find that the formation of the latent image depends not only on the number of quanta absorbed but also on the rate at which they are fed in, and on the temperature. Much attention has recently been paid to the 'reciprocity breakdown' of photographic materials. In Fig. 2 is plotted for various temperatures the exposure, that is, the number of quanta necessary to produce a
It seems that we have arrived at a fairly simple picture of the mode of action of photographic materials, but it should be pointed out that the picture is by no means complete and will not be regarded as correct by all workers in this field. There is space for mention only of a few more facts which seem important and which cannot or can only partly be explained by our picture. There is solarization, the fact that on prolonged exposure development leads to a partly reversed image ; desensitizing by dyes, whereby the material is made insensitive to further exposure while still remaining developable; reversal by dyes, where the latent image is destroyed by subsequent exposure in the absorption band of the dye; and many more. But our picture may be useful as a working hypothesis for future experiments.

W. F. BERG. 